\title{
CALDO DE LAMBRETA: ETNOGRAFIA DOS SABERES DA TRADIÇÃO NA ATIVIDADE EXTRATIVISTA DAS COLETORAS DA LUCINA PECTINATA NA VILA DE GARAPUÁ, CAIRU - BA
}

\author{
LAMBRETA BROTH: \\ ETHNOGRAPHY OF TRADITION \\ KNOWLEDGE IN ACTIVITY \\ OF GATHERERS OF LUCINA \\ PECTINATA IN THE VILLAGE OF \\ GARAPUÁ, CAIRU - BA
}

\section{Laitta Santiago}

laitasantiago@hotmail.com

Antropóloga pela Faculdade de Filosofia e Ciências Humanas da Universidade Federal da Bahia.

\section{RESUMO}

Este estudo visou conhecer a coleta de um molusco chamado de lambreta (Lucina pectinata) por marisqueiras na vila de Garapuá, Cairu, no Baixo Sul baiano, perpassando pelas artes de pesca, organização do trabalho, saúde ocupacional e as melhores condições de tempo e maré. Utilizou-se o método etnográfico com diários de campo, entrevistas e registro fotográfico. Os grupos de trabalho das marisqueiras são formados majoritariamente por mulheres que fazem rodízios na exploração dos mangues, em cinco jornadas semanais de quatro horas diárias de trabalho. Cada integrante obtém em torno de dez dúzias de lambreta por dia, vendidas a atravessadores a preços abaixo do valor de mercado. A coleta do animal - localizado através de um fio d'água subindo à superfície - é feita com a mão ou com o uso do facão e condicionada pelas fases da lua, pelo fluxo das marés e pelo caráter agreste do ecossistema manguezal. As coletoras levam consigo o samburá (um cesto para carregar peixe), alimentação, vestimenta e óleo diesel, usado como repelente. A diminuição dos estoques naturais de lambreta leva as marisqueiras a aumentar as horas de trabalho no mangue e as distâncias percorridas, assim como a desejarem abandonar a tradicional atividade, buscando outras fontes de renda, como o beneficiamento do camarão.

Palavras-chave: Saberes da tradição de marisqueiras. Lambreta. Garapuá.

\section{ABSTRACT}

This study aims to carry out the gathering by hand of a mollusc called 'Lambreta' (Lucina pectinata) by shellfish gatherers in the village of Garapuá, Cairu, in Southern Bahia, Brazil, including the fishing gear, work organization, occupational health and better weather and tide conditions. We used the ethnographic method with daily field diaries, interviews and photographic record. The working groups are composed mostly 
by women who take turns in the exploitation of mangroves, working five days a week, four hours a day. Each member collects around ten dozen lambretas per day, which are sold to middlemen below market prices. The molluscs gathering - identified by a trickle of water rising to the surface - is done by hand or using a machete and it is conditioned by moon phases, tidal streams and the wild features of the mangrove ecosystem. The collectors take with them the samburá (a kind of creel), food, clothing and diesel oil, used as insect repellent. The decline in natural stocks of lambreta forces collectors to increase their working hours in the mangroves and the distance traveled, as well as it makes them want to leave this traditional activity, and seek for other sources of income such as shrimp processing.

Keywords: Traditional knowledge of shellfish gatherers. Lambreta. Garapuá.

\section{APRESENTAÇÃO}

Este estudo teve como tema o modo de vida e o trabalho feminino na pesca artesanal na vila de Garapuá, comunidade tradicional costeira pertencente ao município de Cairu na microrregião do Baixo Sul baiano e à Área de Proteção Ambiental (APA) Tinharé-Boipeba' ${ }^{1}$ O objeto de pesquisa foi o arsenal cultural encerrado na mariscagem, que permite a inserção da mulher pescadora - população desta pesquisa - no complexo ecológico marinho e estuarino, com ênfase na atividade extrativista de Lucina pectinata (GMELIN, 1791).

Esse molusco ${ }^{2}$ bivalve $^{3}$ comestível etnoclassificado como lambreta ou sarnambi ${ }^{4}$ é utilizado na culinária acompanhado por seu caldo temperado com tomate, cebola, coentro e sal e servido em copo americano. Possui grande importância na cadeia produtiva local por ser a principal fonte proteica animal de exploração feminina na comunidade, abastecendo mercados de localidades como Salvador, Valença, Morro de São Paulo e Garapuá. O objetivo central desta pesquisa é descrever o modo de vida das marisqueiras que exploram o nicho ecológico do manguezal através da coleta da lambreta na vila de Garapuá, em um contexto de abandono social e institucional, de expansão da especulação imobiliária e das indústrias petrolífera e turística. Para tanto, foi central a identificação dos principais conhecimentos tradicionais e das tecnologias que permitem às marisqueiras a exploração desse molusco, e das limitações enfrentadas por elas no processo produtivo diante da redução dos estoques naturais desse animal, provocada pela sobre-exploração dos manguezais ${ }^{5}$ adjacentes à comunidade. Assim, adotou-se um recorte que visou registrar, dentro dos limites da proposta metodológica adotada, os saberes e as práticas construídos na relação com o meio ambiente no processo de trabalho realizado pelas marisqueiras no extrativismo da lambreta na vila de Garapuá, Cairu (BA), seu estoque de conhecimento acumulado sobre a dinâmica da reprodução ambiental do complexo ecológico e dos recursos naturais que aí ocorrem. Para dar conta dos limites do objetivo proposto, buscou-se identificar, descrever e analisar, no arsenal cultural da mariscagem da lambreta na comunidade, os conhecimentos tradicionais sobre artes e instrumentos de pesca utilizados na exploração do molusco; as melhores condições de tempo e de maré para a realização do trabalho; a organização laboral e de comercialização; a saúde ocupacional; além de prover subsídios à formulação de políticas públicas e projetos de intervenção dirigidos à promoção do trabalho feminino na pesca.

São ainda tímidos os esforços da gestão pública de inclusão dos trabalhadores artesanais do setor da pesca na construção de políticas públicas para a categoria, desprezada por pacotes de políticas que consideram apenas interesses econômicos, sequer reconhecendo a existência dessas comunidades, restringindo seu acesso à terra e negando-lhes direitos trabalhistas e previdenciários. Essa exclusão evidencia uma insuficiência representante da falência dos 
instrumentos democráticos. Sua demografia é imprecisa, como a estatística pesqueira e aquícola no país. Segundo dados do Ministério da Pesca e Aquicultura (MPA) (BRASIL, [2011?]), do total de 990 mil pescadores registrados em 2011, 985 mil são artesanais, o que representa $99,11 \%$ do contingente de pescadores, contra apenas $0,89 \%$ da pesca industrial.

No caso da pesca feminina, os números oficiais estão ainda mais distantes da realidade, uma vez que mulheres que realizam atividades extrativistas são enquadradas em pesquisas nas categorias "desempregada" ou "dona de casa". Existem alguns instrumentos institucionais que protegem ou deveriam proteger populações tradicionais, a atividade da pesca tradicional e seus territórios. Sabe-se, porém, que na prática a maioria desses instrumentos são ineficientes. A Constituição Federal de 1988, nos Artigos 215 e 216, estabeleceu que o patrimônio cultural brasileiro é composto por bens de natureza material e imaterial, sendo o último também chamado de patrimônio cultural intangível, definido pela Organização das Nações Unidas para a Educação, Ciência e Cultura (Unesco) como "as práticas, representações, expressões, conhecimentos e técnicas junto com os instrumentos, objetos, artefatos e lugares culturais que lhes são associados", que as comunidades, grupos e indivíduos reconhecem como parte integrante de seu patrimônio cultural7.

Amparado nos artigos mencionados, este estudo objetivou acessar os saberes e fazeres artesanais do trabalho dentro da cosmovisão das mulheres que subsistem da mariscagem da lambreta na vila de Garapuá - onde são chamadas de "lambreteiras" - e defender a valorização e a salvaguarda do patrimônio cultural imaterial ou etnopatrimônio que é a pesca artesanal. Embora o patrimônio cognitivo da mariscagem não seja registrado como bem cultural nem inventariado pelo Instituto do Patrimônio Histórico e Artístico Nacional, o saber acumulado em torno da coleta da lambreta traduzido neste trabalho, mesmo implicando um levantamento elementar de seus etnoconhecimentos e indicações sumárias pouco refinadas do repertório de conhecimentos ambientais dessas mulheres, retrata a mariscagem como patrimônio étnico por sua relevância cultural e econômica e por ser reconhecida como valiosa pelas comunidades pesqueiras.

\section{ITINERÁRIO DE PESQUISA}

O estudo foi realizado dentro das atividades do Projeto Marsol Maricultura Familiar Solidária no Baixo Sul Baiano, pertencente a um programa que atua na região executando projetos de extensão em transmissão de tecnologias em maricultura artesanal (ACCIOLY, 2005). Ao buscar, a partir de uma perspectiva antropológica, compreender as práticas e as visões de mundo associadas à mariscagem, este estudo etnográfico realizado durante onze meses se coloca à luz da antropologia interpretativa defendida por Clifford Geertz (1989), utilizando na produção dos dados primários técnicas qualitativas como observação participante com marisqueiras vivendo em Garapuá, que incluem tanto registros de conversas informais associadas ao tema do estudo quanto registros mediados por fotografia de práticas cotidianas que traduzem etnoconhecimentos.

Com uma amostragem intencional não probabilística por meio da técnica bola de neve (snowball sampling) (CAULKINS; HYATT, 1999), e usando do critério da saturação da informação, foram realizadas pela pesquisadora três entrevistas em profundidade, com duração de 45 a 60 minutos cada, com experientes marisqueiras de diferentes idades, estado civil e número de filhos. As entrevistas foram realizadas nas residências das interlocutoras de pesquisa, gravadas em meio eletrônico analógico e posteriormente transcritas. A análise 
implicou no ordenamento dos dados qualitativos em categorias relacionadas à pesca praticada por mulheres (conhecimentos tradicionais sobre a exploração da lambreta, artes e instrumentos de pesca, condições de tempo e maré, organização do trabalho e saúde ocupacional), respeitando o linguajar nativo, visando mapear a diversidade das representações ligadas à mariscagem da lambreta e compreender a lógica que lhe é subjacente e contextualizando discursos e práticas em seu contexto socioeconômico e cultural mais amplo.

\section{SINAIS DE MEMÓRIA NO RETRATO DA COSTA}

A Costa do Dendê, microrregião do Baixo Sul baiano, dista $120 \mathrm{~km}$ ao sul de Salvador é entrecortada por estuários ${ }^{8}$ e baías, com manguezais e ilhas. Garapuá está localizada entre o rio Garapuá e o mar na costa leste da Ilha de Tinharé, uma das quatorze ilhas que formam o arquipélago de Tinharé no estuário do rio Una. A enseada de mil metros de largura ${ }^{9}$ em forma de meia lua, cercada por coqueiros altos e protegida nas duas extremidades por recifes rochosos e coralinos, fica a uma hora de barco por mar aberto ou a uma hora e trinta minutos de trator do balneário internacionalmente conhecido, Morro de São Paulo. Após a ponta ao sul começa a deserta Praia do Pratigi e caminhando por trinta minutos chega-se à Praia do Pontal, onde está o fim da ilha de Tinharé, em frente à ilha de Boipeba. A área de Garapuá possui praias, manguezais, restingas e recifes de coral, diferentes ambientes naturais integrados em uma ilha. Em estudo etnoecológico da pesca artesanal de Garapuá, Mendes (2002) mapeou ambientes, pescados e artes de pesca dessa comunidade, descrevendo os ambientes explorados como manguezal, arrecife ${ }^{10}$, enseada e a categoria êmica lá fora, como sendo todo o mar fora da enseada. A principal atividade produtiva é a pesca de arrastão ${ }^{11}$ do camarão marinho (Penaeus brasiliensis e Xyphopenaeus krogeri), mas diferentes artes de pesca são utilizadas a depender das diversas espécies de peixes. São importantes ainda a pesca da lagosta vermelha (Panulirus echinatus), a captura do polvo-verdadeiro (Octopus vulgaris), a mariscagem da lambreta (Lucina pectinata) e a extração do caranguejo-uçá (Ucides cordatus). Os homens realizam a pesca de peixes, camarões e lagostas, e a captura do polvo e do caranguejo, enquanto as mulheres realizam a mariscagem de espécies de organismos da cadeia alimentar que vivem na lama e nas massas de água estuarinas adjacentes, além do beneficiamento do camarão e do pescado. O vilarejo de Garapuá, que recebeu o nome de um pássaro típico da região e foi registrado como povoado apenas em 2000 (ICÓ, 2007), teve o processo de povoamento iniciado há cerca de 150 anos com a chegada de fazendeiros.

Figura 1 - Futebol de meninos na baía

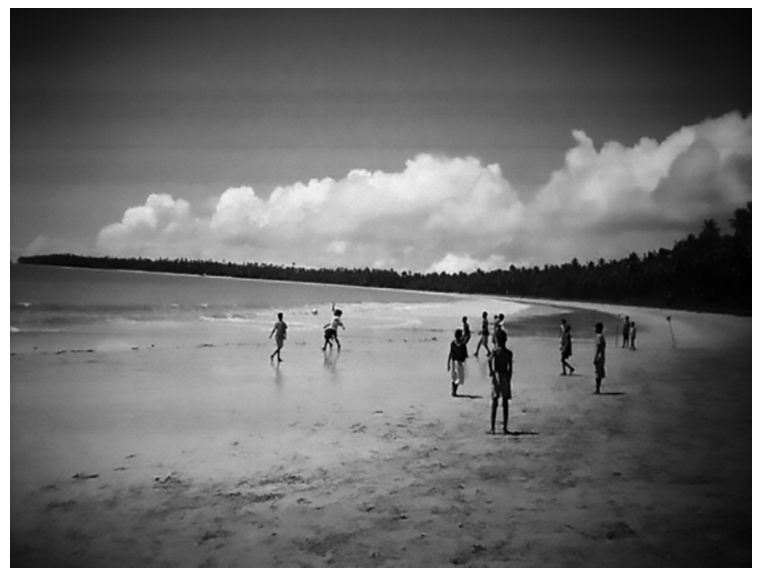

Fonte: Acervo da autora 
Figura 2 - Lambreta em barraca de praia

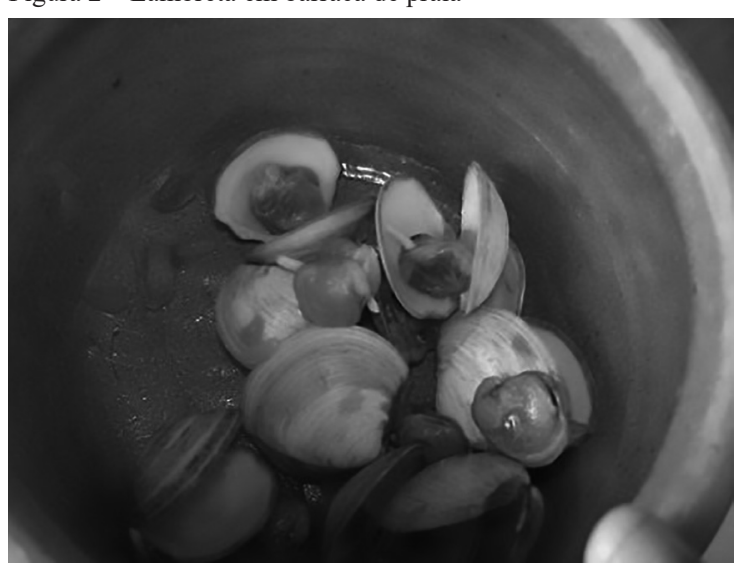

Fonte: Acervo da autora

O morador do povoado Carlos Aguiar conta a história que ouviu de sua família $^{12}$, segundo a qual seu bisavô Coutinho começou a ir à ilha remando de canoa de Valença até Garapuá, onde começou a plantar árvores frutíferas e levar para vender na feira de Valença. O território da comunidade é tomado por duas fazendas de coco e inicia-se então a migração de famílias para o trabalho agrícola; o vilarejo começa a se formar e crescer como ponto de apoio de pescadores e funcionários das fazendas. Depois de estabelecidas, essas famílias também pediam permissão aos fazendeiros para plantar pequenas roças, assim como realizar extrativismo de frutos e coleta de lenha seca, atividades essenciais para a reprodução dos grupos pesqueiros (WOORTMANN, 1992). Segundo história oral contada na comunidade, na década de 1960 ocorria apenas a pesca de subsistência, quando um morador chamado de Seu Alberísio, acompanhado de outro homem conhecido como Cuta, tiveram papel importante na pesca de Garapuá ao passarem a trazer barras de gelo de Valença e improvisar geladeiras na beira da praia feitas com caixas de zinco cheias de pó de serra. A exploração da lambreta em Garapuá também foi iniciada nesse período por Seu Alberísio, que comercializou pela primeira vez o animal no Mercado Modelo de Salvador em uma época em que não havia a cultura de consumo desse molusco na capital. A partir daí o extrativismo da lambreta com fins de exploração comercial se desenvolveu junto com a pesca e atraiu mais famílias, que migraram para a vila no intuito de explorar esse recurso.

A colonização da população deste estudo consiste no registro, através da Colônia de Pescadores e Aquicultores Z-55 sediada no município de Cairu, para o recebimento da carteira da colônia e do seguro desemprego do defeso do camarão. Esta pesquisa estimou um mínimo de 25 a 30 pessoas que trabalhavam na mariscagem da lambreta em Garapuá. Delfino (2005) estimou em Garapuá o quantitativo de coletores de mariscos de 30 pessoas, enquanto Pellegrini (2010) estimou entre 15 e 30 pessoas por dia trabalhando no manguezal ou no percurso entre o local e o povoado. Segundo dados de Pellegrini (2010), em novembro de 2007 o cadastro da Colônia de Pescadores Z-55, incluindo homens e mulheres, registrava 37 marisqueiros, sendo 33 do sexo feminino. Entretanto, conforme relato da secretária da Colônia Z-55 em Garapuá, muitas pessoas ainda não haviam se cadastrado por não acreditarem nos benefícios advindos da filiação ou mesmo por não terem condição de pagar a mensalidade de $\mathrm{R} \$ 10,00$, o que aponta um quantitativo maior de pessoas trabalhando nessa atividade. No ano de 2010, segundo depoimento da mesma secretária, o quantitativo de marisqueiras totalizava 180 pessoas, sendo 110 mulheres e 70 homens. Por outro lado, ela ressalva que nem todas as pessoas inscritas na Z-55 são coletoras assíduas e que algumas atuam tanto no manguezal quanto nos recifes, na coleta de polvo, de siri e pesca de linha.

Pellegrini (2010, p. 94) diz que, para a comunidade, o espaço insular não é paradisíaco ao apresentar-se como frágil e instável, onde transcorre uma 
vida cotidiana dura e difícil. A população marcadamente afrodescendente que habita Garapuá é estimada atualmente em mil habitantes. A divisão social do espaço é bem demarcada, e se dá através da separação em dois polos, chamados por eles de Rua da Praia ou "parte baixa" e Ponta da Areia ou "parte alta". A Rua da Praia está em frente à praia, onde há casas de veraneio, algumas remanescentes casas de nativos, um pequeno número de pousadas, assim como oito barracas de praia e uma profusão de pequenos comércios, como mercados que vendem suprimentos alimentares simples. A vila de Garapuá possui pequena extensão norte por ser cercada por um grande manguezal (Panan), e na extensão sul está situada a fazenda de coco Quadro, que pertenceu à família Costa Lima e hoje pertence ao banqueiro Daniel Dantas.

É essa fazenda que, além de ocupar quase todo o território da comunidade e limitar seu acesso à terra, divide a comunidade em parte alta e parte baixa. No passado, a maioria das famílias de pescadores residentes em Garapuá tinha suas casas localizadas em frente ao mar. A comunidade apresenta um razoável aumento populacional, e mesmo quando as famílias ainda viviam à beira-mar, na medida que os filhos de pescadores nativos casavam e novas gerações chegavam, as residências tornaram-se superlotadas, até que começaram a reivindicar do então gestor municipal uma alternativa de moradia para a população, resultando no oferecimento de lotes na Ponta da Areia, local que veio a ser chamado de vila Garapuá Nova. Esse loteamento, próximo à lagoa que abastece a comunidade e à trilha para o porto de Garapuá, foi ocupado pelas famílias de pescadores. A mudança das famílias nativas da beira da praia para o loteamento chamado Garapuá Nova, iniciado em 1992, deu-se através de uma negociação entre um gestor do município de Cairu e um fazendeiro a respeito de lotear e doar aos moradores um pequeno pedaço de terra antes usado pelos nativos como depósito de lixo. Já prevendo a favelização do local, o dono da terra sugeriu ao prefeito que desse o terreno aos nativos já com as casas construídas, mas cada família apenas recebeu seu lote e foi responsável por construir sua residência.

\section{CONHECIMENTOS TRADICIONAIS E TECNOLOGIAS NO SAVOIR-FAIRE DE LAMBRETEIRAS}

Explorada por todo o ano em Garapuá durante os meses chuvosos, quando a maioria dos pescadores não pode exercer suas atividades em função do mau tempo, é a atividade extrativista da lambreta que sustenta a economia doméstica do vilarejo (FUNDAÇÃO ONDAZUL; UNIVERSIDADE FEDERAL DA BAHIA, 1999 apud POGGIO, 2001, p. 15), motivo pelo qual mulheres que não desejam trabalhar no mangue migrem para as cidades de médio e grande porte. A rotina de preparação para o trabalho no mangue começa sempre por arrumar uma sacola contendo objetos para serem levados, como uma roupa usada apenas durante a permanência na lama, trocada assim que chegam ao local; um tecido torcido chamado de rodilha ${ }^{13}$ colocado na cabeça para ajudar no apoio ao carregar o samburá14 - um cesto artesanal onde a lambreta é carregada -; e um lenço usado para proteger os cabelos da lama. As pernas das marisqueiras ficam cobertas pela lama na coleta, por isso devem usar short para facilitar o deslocamento na lama. Como estratégia de proteção contra a mutuca (Tabanus sudeticus) ${ }^{15}$, mosca cuja picada é dolorida, vestem ao mesmo tempo dois shorts confeccionados com tecido grosso. Integra ainda a preparação para o trabalho no mangue o uso do óleo diesel, chamado de óleo de barco ${ }^{16}$, ou de querosene para repelir mosquitos, produto passado em todo o corpo e rosto, causando muitas reações alérgicas - outra medida para proteger a pele contra os mosquitos é vestir sobre a roupa uma camisa de manga 
e sem decote. Também não podem deixar de levar alimentos: quando a maré é cedo são levados pães e biscoitos e quando a maré é tarde, levam almoço. No final, lavam-se em uma poça d'água ou rio e trocam de roupa novamente para voltar para casa.

A Lucina pectinata é, segundo Assis (1978 apud POGGIO, 2001, p. 22), um molusco que vive normalmente em zonas de águas calmas, encontrado enterrado em substrato lodoso de manguezais em profundidade que varia de quinze a vinte centímetros e posicionado verticalmente de forma que sua concha permaneça com o umbo (ápice) voltado para a superfície. Para Narchi e Assis (1980 apud POGGIO, 2001, p. 23), esse animal bivalve cavador de fundo mole tem o hábito de construir no substrato uma espécie de tubo anterior utilizando o pé e, por isso, tende a permanecer por longos períodos no mesmo lugar. Assis (1978 apud POGGIO, 2001, p. 22) diz que esse molusco filtrador se alimenta a partir de seu sifão de depósitos de plâncton e de matéria orgânica particulada ou dissolvida encontrados na água dos manguezais, trazidos, conforme Ruppert, Fox e Barnes (2005 apud SOUTO; MARTINS, 2009, p. 212), da superfície para dentro da cavidade do manto. Para Narchi e Assis (1980 apud POGGIO, 2001, p. 23), a corrente de água que passa pelo interior desses animais entra pelo tubo anterior, sendo a principal corrente inalante, e sai pelo sifão exalante localizado posteriormente - na maré baixa pode-se observar a circulação da água através dos pequenos orifícios deixados no substrato por essas vias de passagem, e assim os animais são facilmente localizados.

A pesca da lambreta em Garapuá recebe a denominação de catar, mariscar e tirar. Os bancos pesqueiros da lambreta são identificados pelo chamado olho ou suspiro da lambreta ${ }^{17}$, um fio d'água que sobe à superfície da lama saindo da cavidade pela qual o animal se alimenta, o que indica sua presença. Depois de identificada, para encontrá-la é preciso cavar embaixo das raízes de floresta de mangue (Rhizophora mangle) chamadas de quizambas ou quizangas ${ }^{18}$ e então puxá-la do fundo da lama para a superfície. Deve haver um rigoroso controle no ato da coleta, já que além das lambretas saudáveis são encontradas também lambretas estragadas e desaconselháveis ao consumo.

As marisqueiras desenvolvem diferentes habilidades ao realizar o extrativismo da lambreta com as mãos ou com a ajuda de um facão. Na coleta com as mãos, a posição de procura do animal consiste em curvar o tronco e voltar a cabeça para baixo, colocar braços e mãos dentro da lama e cavar até encontrar cada molusco, que é retirado e colocado em uma vasilha. Já em habitats ${ }^{19}$ como as raízes das florestas de mangue, as marisqueiras não enterram completamente o corpo na lama, uma vez que o facão auxilia na procura da concha do molusco. Após encontrada, utilizam também o facão para abrir um pouco o mangue e escorregar a mão por ele até alcançar a lambreta e retirá-la. Faz-se, segundo Esteves (2007, p. 56), "um movimento com o facão na lama até ressoar o barulho da ponta do facão encostando-se à lambreta, quando o marisco é achado ele é retirado com a mão, num movimento que empurra o braço até a altura do cotovelo na lama". Como insumos, cada lambreteira precisa de vasilha, samburá, cesto, um saco de cebola e um frasco contendo óleo diesel. Essa atividade artesanal de pequeno porte tem sido comprometida, uma vez que os artesãos que ainda fazem o samburá e outros instrumentos de pesca na comunidade vêm tendo dificuldade em encontrar a matéria-prima, a palha de canabrava (Erianthus sccharoides) ${ }^{20}$.

Além do extrativismo da lambreta, foram elencadas ainda outras atividades produtivas femininas que dependem do domínio de diferentes artes de pesca, como a extração da ostra, a captura do caranguejo-uçá de andada ${ }^{21}$, do polvo-verdadeiro e do siri, e a pesca de calão de peixes, camarões e lagostas. Das artes de pesca citadas, a pesca de calão, a captura do polvo e do caranguejo de braço são tradicionalmente predominadas por homens. Depois da coleta da 
lambreta, o beneficiamento do camarão proveniente da pesca de arrastão em Garapuá é a segunda atividade a que essas mulheres mais se dedicam, conforme afirmação "Eu cato camarão, além de mariscar, o que eu mais faço mesmo é descascar camarão"22. O camarão é catado para fazer filé, o processo de catação consiste em retirar as cascas e a cabeça, lavar, limpar e ensacar para a venda, em geral congelada. Pode-se observar o processo de migração da mulher da extração da lambreta para o beneficiamento do camarão.

Figura 3 - Encontro de grupos no mangue

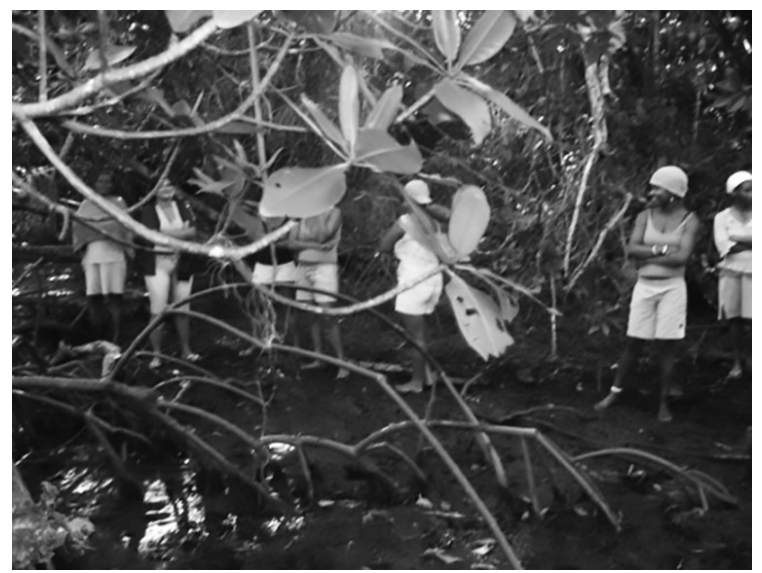

Fonte: Acervo da autora

Figura 4 - Marisqueiras tratam peixes

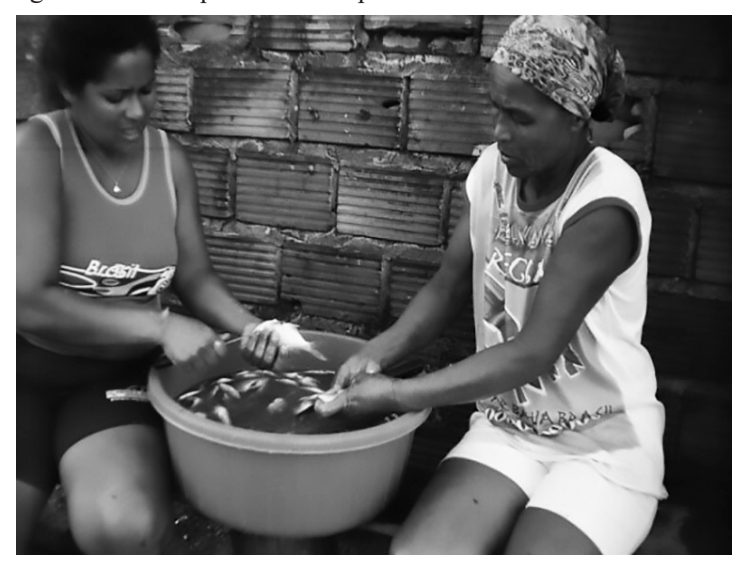

Fonte: Acervo da autora.

Outra atividade importante é o beneficiamento do pescado chamado de tratar e secar peixe (SANTIAGO, 2013, 2014), proveniente tanto da pesca feminina como da realizada pelo companheiro, seja para consumo doméstico ou para comercialização. Esses peixes são tratados e secos em precárias condições de higiene, uma vez que ficam expostos a vento e poeira, moscas e outros insetos, lagartixas e animais domésticos como gatos e cachorros. Além dos trabalhos relacionados direta ou indiretamente à pesca, há ainda outras importantes atividades desenvolvidas pelas marisqueiras em sua dupla jornada de trabalho: as tarefas domésticas em suas próprias casas (preparo da alimentação, lavagem de roupas, limpeza e arrumação da casa) - cumprindo 154 sua atribuição histórica de cuidado do lar e dos filhos -, aos sábados e domingos, ainda mais do que nos dias de ida ao mangue, as mulheres se dedicam ao trabalho doméstico acumulado durante a semana. Exercem também atividades como a lavagem de roupa para outras famílias; o trabalho em pequenos estabelecimentos comerciais, como barracas de praia; o preparo e venda de alimentos salgados e doces (SANTIAGO, 2013, 2014); e a prestação serviços para a colônia de pesca de Cairu, como tesoureira em Garapuá, efetuando cobranças na comunidade. 


\section{TEMPO ECOLÓGICO: CONDIÇÕES DE TEMPO E CICLO DAS MARÉS}

A partir da etnologia do povo sudanês Nuer, Evans-Pritchard (2007) comenta que as relações sociais dos Nuer são influenciadas por limitações ecológicas e segundo seus conceitos de tempo - quando reflexo de suas relações com o meio ambiente é chamado de "tempo ecológico", no qual a seleção de pontos de referência é determinada pela significação que as mudanças naturais têm para as atividades humanas, logo, apresentam maior facilidade de falar do tempo em relação às atividades que executam ao invés de abstratamente ou em números. De acordo com Huguenin (2005, p. 28), enquanto o homem moderno guia-se pelo tempo do relógio, os que vivem segundo um gênero de vida tradicional, associam suas atividades sociais com os ritmos da natureza, a percepção de tempo nas comunidades pesqueiras não é linear como no mundo moderno, mas um tempo ecológico articulado com a natureza; o tempo circular dos ciclos diários, lunares, solares anuais e sazonais, associado ao gênero de vida dessas populações que possuem conhecimentos sobre ventos, fases lunares e marés que instruem sobre a atividade pesqueira. Conforme constata Mendes (2002), a pesca da lambreta sofre a influência dos ciclos naturais/do tempo.

As condições de tempo são descritas neste trabalho sob os binômios inverno e verão, chuva e sol, e frio versus calor. Em Garapuá, o verão foi apontado pelas entrevistadas como estação em que mais trabalham na mariscagem. Os motivos apontados para a preferência de mariscar no verão é o sol e a crença de que nesse período conseguem encontrar a lambreta mais facilmente. Outras entrevistadas disseram pensar que o verão é o melhor período para o trabalho apenas pelo aumento na demanda e no valor do produto; enquanto no inverno, pelos altos índices pluviométricos da região, a chuva é colocada como obstáculo e até como empecilho para o trabalho, fazendo-as trabalhar menos dias nessa estação, indo ao mangue de duas a três vezes por semana. Exposição à chuva e sol faz parte da rotina dessas mulheres, mas intensos temporais podem inviabilizar o trabalho. A chuva é sempre descrita como inconveniente e um contratempo ao trabalho, pois quando se posicionam para mariscar com a cabeça baixa, a água da chuva entra nos olhos, nariz e ouvido. Além da chuva, a baixa temperatura da lama e fortes ventos também se apresentam como condições adversas, visto que além do desconforto, elas expõem-se ao risco de adoecimento.

Durante o período estudado por Poggio (2001), a temperatura da água na baía de Garapuá apresentou pouca variação, com média anual de $26^{\circ} \mathrm{C}$, atingindo mínima de $25^{\circ} \mathrm{C}$ em junho, julho e agosto e máxima de $29^{\circ} \mathrm{C}$ em janeiro e fevereiro de 2001. Neste estudo, as lambreteiras observaram que no inverno a lambreta era encontrada em maior quantidade do que no verão por causa de sua movimentação vertical no mangue - com a temperatura da lama mais baixa em tempo mais frio, o molusco vai para a superfície; enquanto no verão a lama esquenta e a lambreta vai para o fundo, tendo a marisqueira que enterrar-se mais na procura e sendo mais difícil encontrá-la. Segundo Mendes (2002), durante o inverno encontra-se maior quantidade de indivíduos da $L$. pectinata, porém o tempo frio e chuvoso dificulta o trabalho e causa maior desgaste físico das marisqueiras. A dificuldade de encontrar a lambreta é maior durante o verão devido a migração vertical provocada pela temperatura elevada da lama, fazendo com que os moluscos afundem à procura de lama mais fria; enquanto no inverno, quando a lama se encontra fria elas sobem facilitando o trabalho, resultados próximos aos encontrados por Souto e Martins (2009) com marisqueiras de moluscos bivalves no Distrito de Acupe no Recôncavo Baiano, onde no verão o aumento da temperatura provoca a morte de mariscos ou seu deslocamento para outras áreas por conta do aumento da temperatura da água. A maior abundância no inverno também foi explicada pelo menor esforço de 
captura nessa época, embora a produção sofra impacto negativo por causa das chuvas que se tornam empecilho para a realização da atividade da mariscagem todos os dias. Souto e Martins (2009) atentam para a diferença existente entre maior produção (rendimento de captura) e maior abundância (quantidade de marisco), nem sempre interpretada da mesma forma durante as entrevistas, de maneira que pode haver períodos nos quais, mesmo ocorrendo mais marisco, a produção é menor.

Na taxonomia local, sistema de significados que classifica as espécies através da linguagem, a variação das marés se dá através de critérios temporais, sendo um ciclo mensal referente às alternâncias semanais orientadas pela lua, e um ciclo diário referente a alternâncias do período de um dia (ESTEVES, 2007). O ciclo mensal varia entre maré grande seguida de uma maré intermediária quebrando ou morrendo - e maré morta seguida de outra maré intermediária - de lançamento -, cada uma com duração de uma semana, sendo que no período de maré grande, apontada como a melhor maré por encher e vazar cedo, "o volume de água aumenta e diminui em toda a sua capacidade, o mangue é inundado pelas águas, a maré 'lava o mangue"” (ESTEVES, 2007, p. 7), mostrando melhor os olhos da lambreta.

Foram citadas ainda outras marés: a maré cabeça d'água é a de maior amplitude do mês e acontece um dia depois da mudança para a lua cheia ou nova; a maré de lua ocorre no período de lua crescente; enquanto na maré de mosquito são literalmente atacadas por nuvens de insetos em toda pele do corpo que estiver descoberta.

O Núcleo de Estudos Interdisciplinares sobre a Mulher e o Instituto Brasileiro de Meio Ambiente (1995) acentuam que o movimento das marés torna a área de manguezal inacessível na maré cheia e à noite, um dos fatores limitantes que incidem sobre o tempo de trabalho na mariscagem. Durante a maré seca é mais fácil cavar à procura da lambreta. Esteves (2007) observa que essas são variações de maré definidas a partir do horário que ela "entra" no mangue. Se a maré amanhece de vazante, chamada de maré cedeira, é possível trabalhar pela manhã, mas quando a maré amanhece de enchente e começa a esvaziar à tarde, a maré é tardeira e só é possível ir trabalhar à tarde.

Segundo Esteves (2008, p. 6), no período de um dia, a maré varia entre maré de enchente e maré de vazante, em períodos alternados de seis horas. A cada dia a maré muda de horário em cerca de cinquenta minutos, "se em um dia ela amanheceu de vazante às oito horas da manhã, no dia seguinte ela irá amanhecer de vazante às oito horas e cinquenta minutos". Para uma marisqueira entrevistada nesta pesquisa em Garapuá, quando a maré é tardeira a quantidade de lambreta retirada é menor do que na cedeira, pois nesta há mais tempo de trabalho no mangue, enquanto na tardeira o tempo passa mais rápido e elas se preocupam com a hora de voltar para casa, tanto por motivos de segurança, devido ao caráter agreste do mangue, quanto por precisarem otimizar o trabalho doméstico, conforme o depoimento "a cedeira é melhor porque a gente entra ela tá seca, daqui a pouco ela vai enchendo a gente trabalha" 24 .

A classificação das marés nesta pesquisa tem afinidade com algumas categorias nativas apresentadas por Souto e Martins (2009) ao registrarem conhecimentos de pescadoras de moluscos a respeito da dinâmica das marés, pois eles também as classificaram como cedeira e tardeira. Ao longo do mês as marés vão se sucedendo e seus horários mudando paulatinamente, o que resulta em fases intermediárias. Há entre as marisqueiras certa preferência por uma ou outra maré, enquanto algumas acham melhor a maré cedeira porque podem chegar em casa a tempo de realizar as atividades domésticas, outras preferem a maré tardeira porque têm mais tempo para mariscar. 


\section{ORGANIZAÇÃO DO TRABALHO}

O modo de exploração da L. pectinata pelas mulheres de Garapuá é intensivo, trabalham no mangue em média de quatro a cinco jornadas - de quatro horas cada - por semana, de segunda a sexta-feira. O número de horas de trabalho diário é também influenciado pela localização do manguezal explorado, devido à distância que terão que percorrer. A escolha da quantidade de dias é medida pela sensação de esgotamento físico e de cansaço que descrevem depois da quarta ou quinta jornada de trabalho semanal.

Durante o extrativismo pode ser destacada a exposição das mãos em constante atrito com vegetação, conchas e pedras, o que faz com que as lambreteiras machuquem as mãos e ocorra a entrada de lama embaixo das unhas, causando inflamação por fungos nos cantos dos dedos - uma das mazelas da profissão apontada ao expor os motivos pelos quais é contraindicado ultrapassar as cinco jornadas de trabalho semanais no manguezal. A composição dos grupos de trabalho se dá por pequenos grupamentos fixos de quatro a cinco integrantes majoritariamente mulheres, com participação de poucos homens, e o critério de escolha das parceiras se baseia nas relações de afinidade. A mariscagem, apesar de vista como trabalho pesado, que consome muita força, é reconhecida pelas pescadoras como autogestionária pelo seu caráter de trabalho informal e sem vínculo empregatício, fator apontado como positivo por poderem gerir seus horários e datas de trabalho, apesar da predeterminação da maré.

Embora Poggio (2001, p. 86) e Delfino (2005) tenham dito que apesar do intenso extrativismo praticado nos manguezais de Garapuá e da "estimativa do padrão da distribuição espacial da população de L. pectinata ter mostrado estar influenciada pelos espaços rarefeitos de indivíduos deixados no substrato através da prática extrativista realizada no manguezal", Poggio (2001, p. 14) tenha reconhecido também que "o intenso extrativismo [da L. pectinata] pode prejudicar o crescimento populacional ou até levar as reservas naturais desses organismos à extinção" e, mais tarde, Mendes (2002) tenha constatado a diminuição nos estoques naturais de L. pectinata em alguns manguezais da comunidade antes bastante frequentados, mas que, na época de seu estudo, não estavam mais servindo para a atividade de mariscagem, ainda assim Poggio (2001) afirmou que a população de L. pectinata parecia suportar a pressão a que estava submetida, uma vez que seu ciclo reprodutivo mostrou-se praticamente contínuo, sugerindo a ocorrência de recrutamentos ao longo de todo o ano na população.

Sendo o tamanho médio da primeira maturação sexual da L. pectinata estimado em $30,0 \mathrm{~mm}$, o comportamento extrativista das marisqueiras ao não capturar indivíduos menores que $40,0 \mathrm{~mm}$, por serem considerados de pequeno porte e de difícil aceitação pelo mercado consumidor, contribui com a preservação da população - já que a densidade populacional observada, com média de 32,3 indivíduos $/ \mathrm{m}^{2}$, não apresentou variações muito diferenciadas ao longo do período estudado, tendo em vista a reposição dos estoques promovidos pelos recrutamentos contínuos à população. Podemos observar discrepâncias entre o discurso reproduzido por todas as pescadoras acessadas neste estudo sobre a redução de população da $L$. pectinata, em que fizeram uso da expressão mangue acabado, e as conclusões de Poggio (2001) e Delfino (2005) sobre o sucesso reprodutivo da espécie nos manguezais da vila combinado ao comportamento extrativista das marisqueiras. Pellegrini $(2010$, p. 88$)$ alerta que no caso de Garapuá "ainda que se observe um sucesso reprodutivo, o aumento do esforço de coleta e/ou alteração nas condições físico-químicas [do mar e do mangue] podem impactar a população deste molusco".

O efeito da sobrepesca ${ }^{25}$ se impõe com a redução dos estoques naturais da lambreta, trazendo dificuldades para atender à crescente e sazonal demanda pelo molusco. Com o aumento de contingente na atividade marisqueira e a 
divisão do espaço produtivo manguezal, tanto com homens que migraram da pesca e da captura do caranguejo quanto com população de outras comunidades de bairros periféricos, como Zimbo de Morro de São Paulo e Toc da Gamboa, a sobrepesca foi apontada pelas marisqueiras como principal fator de origem antrópica que pode estar determinando modificações na dinâmica desse ecossistema ${ }^{26}$, causando a crescente diminuição de reservas naturais de lambreta. As lambreteiras de Garapuá contam que, na época da produção de dados deste estudo, conseguiam coletar entre dez e catorze dúzias do marisco por jornada de trabalho, enquanto em tempos passados conseguiam coletar, cada uma, de vinte a trinta dúzias de lambreta em um período de tempo menor.

Em estudos antecedentes, os números variam com forte tendência ao decréscimo. Poggio (2001) quantifica o extrativismo em cerca de dezenove dúzias de lambreta por dia de trabalho; Mendes (2002) encontrou a quantidade média de trinta dúzias por turno, retirando diariamente entre dez e cinquenta dúzias; enquanto no passado foi relatada a quantidade de sessenta a setenta dúzias de lambreta por maré. Pellegrini (2010) obteve uma média de dezesseis dúzias de lambreta por dia por marisqueira.

A pesca da lambreta acontece nas subáreas da floresta de mangue adjacentes à Garapuá, em canais como Camboa Velha, Canal Novo (Pedarta), Panan e Vilisboa. Através de um manejo comunitário/tradicional de manguezais, utilizam-se estratégias que se constituem em práticas de controle autogeridas pela comunidade diante da sobre-exploração, com o objetivo de mitigar o impacto de sobrecarga no ecossistema. Duas dessas práticas são a realização de revezamentos diários ou semanais na exploração dos manguezais e a avaliação da consistência da lama e da intensidade das pegadas deixadas nela e nas florestas de mangue. Segundo Mendes (2002), existem em Garapuá manguezais lamosos e manguezais arenosos. Os manguezais de areia dura dificultam a penetração da mão em busca do molusco, portanto há menor exploração, não há coleta com a mão e apenas uma minoria de marisqueiras cata lambreta com facão. Além de evitar mangues mais populosos, devem também evitar os lugares recentemente trabalhados dentro do manguezal eleito. Elas são capazes de identificar há quanto tempo o local foi trabalhado através da consistência da lama e da intensidade das pegadas deixadas e nas raízes de floresta de mangue - se o local estiver recentemente remexido, a lama fica mole e as pescadoras afundam mais facilmente, enquanto a lama não trabalhada recentemente fica dura, permitindo que elas se equilibrem e trabalhem cavando durante um longo período, até começarem a afundar, quando novamente deslocam-se no mangue em busca de lama mais firme.

A lambreta não é beneficiada, não sendo necessário desconchar. O tempo máximo de conservação da lambreta antes da venda é de quatro dias sob o risco de perda, que é grande por causa das altas temperaturas - muitas abrem e estragam, principalmente no verão. Ao chegar em casa, a maioria das mulheres coloca as lambretas armazenadas em uma vasilha seca, sem água, mas foi relatado ainda o uso de algumas estratégias de conservação durante os dias em que permanecem na casa das pescadoras: 1. colocar as lambretas imersas em água salgada; 2. espalhar as lambretas no chão sobre um saco de cebola vazio; 3. espalhar as lambretas no chão do banheiro com o objetivo de que o produto absorva a umidade e a frieza; 4. colocar as lambretas em um cesto dentro da água do mar e deixá-las conservando por até uma semana; o cesto é um grande samburá chamado de morão ${ }^{27}$, coberto por palhas de coqueiro e colocado dentro do mar, na água salgada, preso em pedaços de madeira enterrados na beira da praia, até que o produto seja escoado.

De acordo com o Ibama (INSTITUTO BRASILEIRO DO MEIO AMBIENTE, 1995, p. 32), "a inserção dos produtos das marisqueiras no mercado é restritiva e desvantajosa e no circuito da comercialização, parcela do valor do seu trabalho lhe é expropriado". Segundo Pellegrini (2010, p. 80), a venda da 
lambreta é restrita aos atravessadores por eles garantirem a regularidade da compra durante todo o ano, mas o baixo preço estabelecido para a dúzia do molusco causa permanente insatisfação e sentimento de impotência nas trabalhadoras que o autor chamou de "identidade coletiva de imobilismo". A quase totalidade da lambreta mariscada em Garapuá é destinada ao comércio, sendo pouco utilizada para consumo familiar. Lá elas são vendidas tanto à figura do atravessador, para ser enviada à Valença, quanto aos donos de quiosques da praia de Garapuá.

Durante todo o ano, a compra de um dos atravessadores da lambreta que transporta o molusco até Valença ocorria apenas uma vez por semana, às quintas-feiras, enquanto outro atravessador levava às sextas-feiras. Donos de quiosques de praia compram uma cota regular da lambreta durante todo o ano, abrangendo a produção de algumas poucas marisqueiras. Durante a baixa estação, quando há pequeno número de turistas, a lambreta deve ter alto padrão de qualidade representado pela categoria popular lambreta de conta ${ }^{28} \mathrm{e}$ apenas são selecionadas para a compra unidades de tamanho grande. Na estatística descritiva estimada, realizada por Poggio (2001, p. 56), da população da lambreta nos manguezais de Garapuá de outubro de 2000 a outubro de 2001 foi verificada "uma amplitude do peso total entre 2,04 g e 107,53 g, resultando em um peso total médio anual dos indivíduos de $22,20 \mathrm{~g}$ ". Para a variável comprimento total da concha das amostras (POGGIO, 2001, p. 47), observou-se "uma amplitude anual de tamanhos que variou de $21,3 \mathrm{~mm}$ a $64,6 \mathrm{~mm}$, enquanto o comprimento médio anual da população resultou em $41,36 \mathrm{~mm}$ ". As classes de maiores tamanhos possuem baixa ocorrência nas amostras, o que, provavelmente, está relacionado a maior pressão extrativista sobre os indivíduos grandes, uma vez que em Garapuá lambretas menores de 40,0 mm são rejeitadas pelas marisqueiras, em virtude da clientela ser muito exigente quanto ao tamanho do animal (POGGIO, 2001).

No verão, os donos dos quiosques de praia de Garapuá desejavam realizar a compra diária, ou ao menos duas ou três vezes por semana, de duzentas dúzias da lambreta, quantidade bem maior que as habituais cinquenta ou cem dúzias, mas devido à redução de população nem sempre as marisqueiras conseguem coletar quantidade suficiente do molusco para suprir esse mercado. Em função da demanda por maior quantidade, os quiosques também compram lambretas de menor tamanho. Por ter maior demanda advinda do turismo, facilitando na busca por compradores, o verão é considerado pelas marisqueiras o melhor período para comercialização da lambreta, podendo assim selecionar quem paga o melhor preço.

Ao final do turno de trabalho, as marisqueiras que vendiam aos donos de quiosques locais realizavam a entrega diária do produto, de maneira que não tinham que se preocupar com seu armazenamento. Para elas, é preferível vender na barraca, caso haja demanda durante todo o ano, a vender ao comprador de Valença, porque o pagamento é mais seguro, uma vez que era comum o atraso do pagamento a ser feito pelos atravessadores. Durante a alta estação, os donos de quiosque encomendam a produção de outras marisqueiras além das fornecedoras regulares no resto do ano, a ser entregue às sextas-feiras ou sábados. A venda nos quiosques agrada a essas marisqueiras por terem um local de referência onde podem comercializar seu produto em momento emergencial. $\mathrm{O}$ valor pago pelos quiosques é superior ao pago por atravessadores da própria comunidade. Porém, a demanda extra dos quiosques é sazonal e restrita ao verão.

\section{A PESCADORA PESCA A DOR? SAÚDE OCUPACIONAL DAS MARISQUEIRAS}

O suporte público na saúde possui deficiente acesso ao atendimento médico no único posto de saúde da comunidade, que funciona de segunda a 
sexta-feira sob responsabilidade de um técnico de enfermagem. Segundo Pellegrini (2010), a vulnerabilidade social é evidenciada na carência de médicos especialistas; semanalmente recebem a visita de um médico clínico geral e de um dentista e, quinzenalmente, de uma ginecologista para atendimento apenas aos casos mais simples, em função da inexistência de estrutura hospitalar. Em casos graves, o paciente é levado para o município de Valença em uma lancha ambulância denominada pela comunidade de ambulancha ou em um veículo fornecido pela prefeitura. Dentre os atendimentos mais frequentes, destacam-se dores nas costas (lombalgia), hipertensão arterial, doenças de pele, verminoses e insuficiências respiratórias, como asma e bronquite, as três últimas relacionadas às ruas de areia onde coabitam crianças e animais como cães, gatos, cavalos e galinhas.

Em qualquer uma das duas técnicas de coleta da lambreta, com a mão ou com o facão, é preciso curvar o corpo em quase $90^{\circ}$ por longos períodos. Entre as marisqueiras que utilizam o facão há ainda maior incidência de dores torácicas, pois além de terem o corpo curvado, é a técnica descrita como a mais cansativa em função do manejo do instrumento. Entre os sintomas relatados pelas lambreteiras de Garapuá estão reumatismos e dores episódicas ou crônicas em várias partes do corpo como costas e coluna, incluindo pescoço, tórax, cabeça, membros, pés, mãos e articulações. A causa do reumatismo é relacionada ao contato direto com as baixas temperaturas da lama, que chamam de frieza do mangue; são dores mais recorrentes ao acordar pela manhã e ainda cedo se sentem cansadas, tendo dificuldade em levantar-se da cama e realizar as atividades do dia. Além desses sintomas, sentem outras dores que são relacionadas por elas ao peso do samburá com as lambretas sobre a cabeça e à forma como posicionam o corpo durante as longas jornadas de trabalho, exaustão por movimentos repetitivos, nem sempre ergonômicos ao corpo. Sofrem com problemas de coluna e dores nas costas (lombalgias) e pernas, em decorrência da envergadura do corpo durante o trabalho, além de precisarem sempre se levantar num esforço repetitivo para guardar as unidades na vasilha, uma vez que a retirada é individual.

$\mathrm{O}$ que todas as artes de pesca praticadas por mulheres na comunidade têm em comum é o fato de exigir muito da coluna. De acordo com Paiva, Martins e Cova (2011, p. 118), as condições de trabalho expõem as marisqueiras a riscos ergonômicos "devido a posturas inadequadas, movimentos repetitivos intensos e levantamento de peso, gerando lesões osteomusculares". O próprio deslocamento no mangue já é, por si só, tarefa bastante dura e que demanda força física, ainda mais quando carregam peso, principalmente na cabeça. Outros problemas de saúde recorrentes são alergias pelo uso do óleo diesel na pele para se proteger dos insetos; problemas ginecológicos, sendo a causa associada por elas à quentura ou à friagem do mangue; varizes e hipertensão causadas pelo contato direto com ambiente salino; e dores nos olhos por respingo de água salgada do mangue durante a chuva.

São perigos apontados durante o trabalho nos manguezais de Garapuá a exposição ao sol e chuva; o alto risco de tropeços, quedas e cortes com ostras e buzanos (Teredo navalis) ${ }^{29}$, que são moluscos que perfuram madeiras submersas e vegetação do mangue, em função dessas raízes serem cobertas por limo. Esses cortes acontecem por todo o corpo, inclusive nas mãos e nas unhas, não só causados por vegetação e conchas, mas também por vidros quebrados e outros tipos de lixo arrastados para o mangue por correntes marítimas. Além dos cortes nos dedos, a unha é a parte do corpo mais afetada no trabalho no mangue, pois para acessar os estoques dentro da lama é preciso tocar na vegetação e nas pedras submersas. No ato repetitivo de cavar a entrada, o acúmulo de lama nas unhas e cutículas e de pequenos pedaços de madeira causam inflamações por fungos. Outros perigos são as picadas de insetos como mosquitos e mutuca (Tabanus sudeticus), risco de picada de animais de importância médica, como cobras etnoclassificadas como jiboia, surucucu e jaracuçu (nem sempre coincidentes com as classificações científicas) e do peixe caramuru $^{30}$ que tem formato de serpente. 
Caramuru porque agora o mangue tá cheio de pedra, né, ai eles fica procurando caranguejo e siri pra comer e ai ele pega sai, às vezes a gente mete a mão na lama, eles sai do outro lado, porque ele entra no buraco do caranguejo. Que chama furna, né, o buraco onde eles ficam. [...] Teve uma vez que eu vim descalça... Passo, que às vezes a gente vem por baixo, que chama por baixo, é o arrecife e por cima é quizanga, porque quando a gente vem por cima, ai uma vez a gente não queria passar por essa coroa ${ }^{31}$, tava muito atolando, vamo por baixo, descalça, a gente veio descalça, quando a gente veio passando, ah, fica assim no buraco deles, quando a gente passou a perna assim pra andar ele pulou na água, aí a gente correu, né, na carreira, como é que corre descalça? (Zeca, 37 anos, natural de Garapuá, viúva, 2 filhos, religião não declarada)

Como medidas de proteção desenvolvidas contra o risco de quedas e cortes, trabalham em grupos e desenvolvem a habilidade de caminhar sobre as florestas de mangue com o samburá cheio de lambretas na cabeça; contra a picada de insetos como a mutuca, vestem dois shorts jeans, usam camisa com manga comprida e passam óleo diesel ou querosene para efeito repelente; contra ressecamento da pele, usam creme hidratante corporal; contra inflamações no aparelho reprodutor, fazem chás de plantas medicinais como aroeira, babatimão e cansanção.

\section{CONSIDERAÇÕES FINAIS}

Os dados obtidos trazem a riqueza desse acervo cultural patrimonial e a importância de sua salvaguarda. Apesar do valor cultural e proteico dos alimentos, na comercialização uma parcela do custo do trabalho das marisqueiras lhes é expropriado, resultando num nível de renda incompatível com o grau de força de trabalho despendido. Essas mulheres podem viver dos gêneros alimentícios que extraem, mas possuem outras fomes ao serem tratadas como subcidadãs. Torná-las beneficiárias de políticas de promoção do trabalho feminino na pesca seria estímulo para lutarem pela continuidade do padrão reprodutivo do manguezal enquanto banco de alimentos.

\section{NOTAS}

${ }^{1}$ Decreto Estadual n 1.240/1992 cria a Área de Proteção Ambiental das Ilhas de Tinharé e Boipeba no município de Cairu sob a coordenação do Centro de Recursos Ambientais e posteriormente da Secretaria de Meio Ambiente do Governo da Bahia.

${ }^{2}$ Animal com corpo protegido por concha, podendo ser uma como os gastrópodes (ex.: búzios, criminoso, preguari etc.), duas como os bivalves (lambreta, sururu, ostra, chumbinho, gusano etc.), ou concha interna, às vezes quase ausente, como os cefalópodes (polvo e lula), entre outros.

${ }^{3}$ Moluscos que possuem concha composta de duas valvas.

${ }^{4}$ Lucina pectinata (GMELIN, 1791), molusco bivalve constituído por duas conchas ovais semelhantes, de cor branca e opaca, medindo cerca de $9 \mathrm{~cm}$ de comprimento.

${ }^{5} \mathrm{O}$ manguezal é um ecossistema formado na interface do continente com o mar, na região de entremarés, onde se desenvolve floresta arbórea característica, com elevada produtividade biológica.

${ }^{6}$ Oscilação periódica do nível do mar, provocada pelo movimento da lua e do sol em relação a Terra, alternando-se momentos de elevação, a preamar, e de abaixamento do nível, a baixa-mar, provocando correntes de marés em estuários, baías e outras reentrâncias costeiras.

${ }^{7}$ Cf. Instituto do Patrimônio Histórico e Artístico Nacional ([201-]). 
${ }^{8}$ Região que apresenta altas produtividades biológicas, formada pela interface do oceano com um rio.

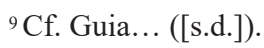

${ }^{10}$ Recife, formação rochosa sedimentar marinha formada por corais, algas calcárias, poliquetas e outros organismos, ou por calcificação do sedimento da praia.

${ }^{11}$ Pesca geralmente de camarão com rede arrastada por barcos motorizados puxadas a uma velocidade que permita a retenção de peixes e mariscos.

${ }^{12}$ Cf. Globo TV; Rede Bahia (2013).

${ }^{13}$ Tecido torcido usado na cabeça para ajudar no apoio ao carregar o samburá.

${ }^{14}$ De origem tupi, é o nome que se dá ao cesto construído com cipós trançados.

${ }^{15}$ Mosca grande encontrada geralmente próxima a corpos d'água, comum nas áreas de manguezal. As fêmeas hematófagas podem dar picadas doloridas que coçam no homem, gado e animais domésticos.

${ }_{16}$ Óleo diesel usado na pele como repelente para mosquitos durante a mariscagem.

${ }^{17}$ Olho D'água, Olho ou Suspiro da Lambreta indicam nesse trabalho o pequeno filete de água que borbulha na superfície partindo da cavidade através da qual a lambreta se alimenta. É a partir deste borbulho que o animal é identificado.

${ }_{18}$ Pés de Mangue, Quizamba ou Quizanga são raízes adventícias do mangue vermelho, uma das principais espécies arbóreas do mangue, própria de solos lodosos, com raízes aéreas. A vegetação estabiliza as margens estuarinas e costeiras, protege a costa contra ações erosivas das ondas e marés e é suporte de fixação de moluscos. Quando raspadas, mostram tonalidade avermelhada.

${ }^{19}$ Local onde vive uma população biológica.

${ }^{20}$ Tipo de capim nativo de terrenos encharcados, de folhas lineares, serreadas, ásperas e cortantes, e inflorescências dispostas em panículas alvas e vistosas, do qual se utilizam dos colmos para construções de coberturas de casas e obras trançadas como armadilhas de pesca.

${ }^{21}$ Período do ciclo reprodutivo que depende da lua, da maré, da salinidade da água e outras condições climáticas, em que fêmeas e machos saem das tocas para acasalamento e, nas andadas seguintes, as fêmeas liberam as larvas, que se desenvolverão transformando-se em nova geração de caranguejos.

22 Entrevista à marisqueira Valdete (33 anos, natural de Garapuá, casada, 3 filhos, católica). ${ }^{23}$ Maré de maior amplitude do mês, que acontece um dia depois da mudança para a lua cheia ou nova. Essa maré recebe esse nome devido ao fenômeno que é ligado a uma enchente rápida nos rios, desencadeando uma enxurrada brusca.

${ }^{24}$ Entrevista à marisqueira Elza (48 anos, natural de Valença, solteira, 5 filhos, católica). ${ }^{25}$ Atividade pesqueira acima da capacidade suporte, por conta ou do aumento da atividade ou da redução dos estoques pesqueiros ou da redução de sua capacidade de recarga.

${ }^{26}$ Sistema ecológico formado pela vegetação, os produtores primários, fauna e micro-organismos, os produtores secundários, que se inter-relacionam através de fluxos de energia e ciclagens de nutrientes, e que garante assim a existência da vida.

${ }^{27}$ Samburá preenchido por lambretas que fica dentro da água do mar preso a pedaços de madeira enterrados na beira da praia, coberto por palhas de coqueiro com o objetivo de conservar o animal.

${ }^{28}$ Lambreta de tamanho grande, muito apreciada por compradores e consumidores.

${ }^{29} \mathrm{O}$ teredo é um molusco de corpo alongado e vermiforme que perfura madeiras submersas.

${ }^{30}$ Moreia. Peixe carnívoro que preda polvos, crustáceos e outros peixes, possui aspecto gelatinoso em formato de serpente e corpo escuro, avermelhado ou esverdeado. Habitam preferencialmente cavidades rochosas e frestas em recifes de corais. Tem mordida perigosa.

${ }^{31}$ Banco de areia costeiro, que descobre na baixa-mar. Baixio costeiro.

\section{REFERÊNCIAS}

ACCIOLY, Miguel da Costa. Maricultura familiar solidária no Baixo Sul Baiano. Salvador: Universidade Federal da Bahia. 2005. 22 p. 
BRASIL. Constituição Federal de 1988. Artigo 215. O Estado garantirá a todos o pleno exercício dos direitos culturais e acesso às fontes da cultura nacional, e apoiará e incentivará a valorização e a difusão das manifestações culturais. Brasília, DF, 1988a. Disponível em: <https://goo.gl/hvGsjX>. Acesso em 22 set. 2013.

BRASIL. Constituição da República Federativa do Brasil, de 5 de outubro de 1988. Diário Oficial da União, Brasília, DF, 5 out. 1988b. Seção 1, p. 1. Disponível em: <https://goo.gl/zaRrL>. Acesso em: 7 dez. 2017.

BRASIL. Ministério da Pesca e Aquicultura. Gestão e ordenamento da pesca artesanal marinha. Brasília, DF, [2011?]. Disponível em: <https://goo.gl/ fP4kf2>. Acesso em: 12 nov. 2013.

CAULKINS, Douglas; HYATT, Susan. Using consensus analysis to measure cultural diversity in organizations and social movements. Field Methods, v. 11, n. 1, p. 5-26, ago. 1999.

DELFINO, Ana Carolina Soares. Estudos complementares da dinâmica de população de Lucina pectinata (Gmelin, 1971), no ecossistema de manguezal de Garapuá - Cairú-Bahia. 2005. Monografia (Bacharelado em Ciências Biológicas) - Instituto de Biologia, Universidade Federal da Bahia, Salvador, 2005.

ESTEVES, Uliana. Saberes do mangue: relação "mulher-ambiente" na comunidade pesqueira de Batateira, Cairú-BA. 2007. 95f. Monografia (Bacharelado em Ciências Sociais) - Faculdade de Filosofia e Ciências Humanas, Universidade Federal da Bahia, Salvador, 2007.

- Mariscagem em Batateira: cognição, classificação e apropriação dos recursos ambientais. In: REUNIÃO BRASILEIRA DE ANTROPOLOGIA, 26., 2008, Porto Seguro. Anais eletrônicos... São Paulo: ABA, 2008.

EVANS-PRITCHARD, Edward. Os Nuer: uma descrição do modo de subsistência e das instituições políticas de um povo nilota. 2. ed. São Paulo: Perspectiva, 2007.

GEERTZ, Clifford. A interpretação das culturas. Rio de Janeiro: Guanabara, 1989.

GLOBO TV; REDE BAHIA. Mosaico Baiano. As belezas do povoado de Garapuá. 2013. 5'30". Disponível em: <https://goo.gl/qhgE48>. Acesso em: 19 nov. 2013.

GUIA de praias - arquipélago de Tinharé, Morro de São Paulo. Tesouro escondido. Bahiasol.com, Salvador, [s.d.]. Disponível em: $<$ https://goo.gl/tFNu3J $>$. Acesso em: 29 abr. 2013.

HUGUENIN, Fernanda Pacheco da Silva. O desencaixe moderno: o "tempo ecológico" de populações tradicionais. Vértices, v. 7, n. 1/3, p. 27-35, jan./dez. 2005 .

ICÓ, Iara. Desenvolvimento local: adaptação ou contestação? As realidades de Barra dos Carvalhos e Garapuá - BA. 2007. Dissertação (Mestrado em Administração) - Faculdade de Administração, Universidade Federal da Bahia, Salvador, 2007.

INSTITUTO BRASILEIRO DO MEIO AMBIENTE. Projeto de desenvolvimento da mulher na atividade pesqueira. Salvador: IBAMA, 1995. 
INSTITUTO DO PATRIMÔNIO HISTÓRICO E ARTÍSTICO NACIONAL. Patrimônio imaterial. Brasília, DF: Iphan, [201-]. Disponível em: <https://goo. gl/jk8Lii $>$. Acesso em: $1^{\circ}$ dez. 2017.

MENDES, Liana Pereira. Etnoecologia dos pescadores e marisqueiras da vila de Garapuá/BA. 2002. 97 f. Monografia (Bacharelado em Ciências Biológicas) - Instituto de Biologia, Universidade Federal da Bahia, Salvador, 2002.

NÚCLEO DE ESTUDOS INTERDISCIPLINARES SOBRE A MULHER; INSTITUTO BRASILEIRO DO MEIO AMBIENTE E DOS RECURSOS NATURAIS RENOVÁVEIS. Diagnóstico socioeconômico e ambiental da mulher pescadora no Recôncavo Baiano. Salvador: NEIM; Ibama, 1992.

PAIVA, Ayane de Souza; MARTINS, Liziane; COVA, Valter Forastieri. O que temos aprendido na convivência com a Ilha de Maré e seus habitantes? In: ALMEIDA, Rosiléia Oliveira; NEVES, Edinaldo Luz. (Orgs.) Caderno Ambiental Ilha de Maré. Salvador: UniJorge, 2011. p. 111-128.

PELLEGRINI, Júlio Augusto de Castro. Vulnerabilidade socioambiental dos manguezais de Garapuá, Cairu/BA frente à inserção da indústria petroleira. 2010. 259 f. Tese (Doutorado em Meio Ambiente) - Faculdade de Educação, Universidade do Estado do Rio de Janeiro, Rio de Janeiro, 2010.

POGGIO, Carolina de Almeida. Biologia quantitativa de Lucina pectinata (Gmelin, 1971) (Bivalvia, Lucinidae) no ecossistema de manguezal de Garapuá. 2001. Monografia (Bacharelado em Ciências Biológicas) - Instituto de Biologia, Universidade Federal da Bahia, Salvador, 2001.

SANTIAGO, Laitta Nogueira. Trabalho na lama: uma etnografia de marisqueiras em duas comunidades tradicionais pesqueiras do Baixo Sul baiano. Revista Ouricuri, v. 3, n. 1, p. 81-96, jun./jul. 2013.

. Caldo de lambreta: uma etnografia das catadoras da Lucina pectinata (GMELIN, 1971) na vila de Garapuá, Cairu - BA. 2014. Monografia (Bacharelado em Ciências Sociais) - Faculdade de Filosofia e Ciências Humanas, Universidade Federal da Bahia, Salvador, 2014.

SOUTO, Francisco José Bezerra; MARTINS, Viviane Souza. Conhecimentos etnoecológicos na mariscagem de moluscos bivalves no Manguezal do Distrito de Acupe, Santo Amaro - BA. Biotemas, v. 22, n. 4, p. 207-218, dez. 2009.

WOORTMANN, Ellen Fensterseifer. Da complementaridade à dependência: espaço, tempo e gênero em "comunidades pesqueiras" do Nordeste. Revista Brasileira de Ciências Sociais, ano 7, n. 18, p. 41-61, 1992. 